\title{
Serum IgG Level Is A Predicting Factor for the Response to Neoadjuvant Chemotherapy In Patients With Esophageal Squamous Cell Carcinoma
}

\section{Seiichi Nakaya ( $\nabla$ nakaya22@med.nagoya-cu.ac.jp)}

Nagoya City University Graduate School of Medical Sciences and Medical School: Nagoya Shiritsu Daigaku Daigakuin Igaku Kenkyuka Igakubu https://orcid.org/0000-0002-7000-6649

\section{Ryo Ogawa}

Nagoya City University Graduate School of Medical Sciences and Medical School: Nagoya Shiritsu Daigaku Daigakuin Igaku Kenkyuka Igakubu

\section{Shunsuke Hayakawa}

Nagoya City University Graduate School of Medical Sciences and Medical School: Nagoya Shiritsu Daigaku Daigakuin Igaku Kenkyuka Igakubu

\section{Shiro Fujihata}

Nagoya City University Graduate School of Medical Sciences and Medical School: Nagoya Shiritsu Daigaku Daigakuin Igaku Kenkyuka Igakubu

\section{Tomotaka Okubo}

Nagoya City University Graduate School of Medical Sciences and Medical School: Nagoya Shiritsu Daigaku Daigakuin Igaku Kenkyuka Igakubu

\section{Hiroyuki Sagawa}

Nagoya City University Graduate School of Medical Sciences and Medical School: Nagoya Shiritsu Daigaku Daigakuin Igaku Kenkyuka Igakubu

\section{Tatsuya Tanaka}

Nagoya City University Graduate School of Medical Sciences and Medical School: Nagoya Shiritsu Daigaku Daigakuin Igaku Kenkyuka Igakubu

\section{Hiroki Takahashi}

Nagoya City University Graduate School of Medical Sciences and Medical School: Nagoya Shiritsu Daigaku Daigakuin Igaku Kenkyuka Igakubu

\section{Yoichi Matsuo}

Nagoya City University Graduate School of Medical Sciences and Medical School: Nagoya Shiritsu Daigaku Daigakuin Igaku Kenkyuka Igakubu

\section{Shuji Takiguchi}

Nagoya City University Graduate School of Medical Sciences and Medical School: Nagoya Shiritsu Daigaku Daigakuin Igaku Kenkyuka Igakubu 
Research

Keywords: Immunoglobulin G, esophageal squamous cell carcinoma, neoadjuvant therapy, chemotherapy

Posted Date: February 2nd, 2021

DOl: https://doi.org/10.21203/rs.3.rs-163369/v1

License: (c) (i) This work is licensed under a Creative Commons Attribution 4.0 International License.

Read Full License

Version of Record: A version of this preprint was published at World Journal of Surgical Oncology on July 19th, 2021. See the published version at https://doi.org/10.1186/s12957-021-02290-7. 


\section{Abstract}

\section{Background}

Despite the established oncological benefits of neoadjuvant chemotherapy for esophageal squamous cell cancer, not all cases demonstrate benefit. Hence, predicting the response to chemotherapy before treatment is desirable. Some reports have shown that immune factors are related to the chemotherapy response. This study aimed to investigate the utility of serum IgG levels for predicting chemotherapy response.

\section{Methods}

Response to chemotherapy and pretreatment serum IgG levels were examined in 77 cases who underwent esophagectomy after neoadjuvant chemotherapy for esophageal squamous cell cancer.

\section{Results}

The effective response group had significantly lower serum IgG levels than the ineffective response group $(p<0.001)$. Univariate and multivariate analyses revealed serum IgG level to be an independent predictor for response to chemotherapy $(p=0.001)$. Furthermore, cases with effective pathological response had significantly lower pretreatment serum IgG levels than those who did not $(p=0.006)$.

\section{Conclusions}

Our finding showed that serum IgG levels can be a predictor of the response to neoadjuvant chemotherapy for esophageal squamous cell carcinoma.

\section{Trial registration}

This retrospective study was approved by the review board of Nagoya City University Graduate School of Medical Sciences (reception number: 60-18-0008).

\section{Introduction}

Esophageal cancer, which ranks seventh in terms of incidence and sixth in terms of overall mortality worldwide, has remained one of the most common malignancies, with esophageal squamous cell cancer (ESCC) being the dominant histological type in East Asia [1].

The oncological benefits of neoadjuvant chemotherapy for ESCC, established by the JCOG9907 trial, has had a major impact on clinical practices [2]. Japanese guidelines for the treatment of ESCC have shown that neoadjuvant chemotherapy comprising 5 -fluorouracil and cisplatin (FP) was beneficial for patients with clinical stage II/III ESCC. Furthermore, a randomized controlled phase III trial comparing FP; docetaxel, cisplatin, and 5-fluorouracil (DCF); and FP-radiotherapy as neoadjuvant treatment for clinical 
stage II or III esophageal cancer (JCOG1109 trial) is currently being conducted, with our department also conducting DCF therapy [3].

Studies have reported that FP and DCF therapy for ESCC had response rates of $38 \%$ and $70 \%$, respectively $[2,4]$. In some cases, however, neoadjuvant chemotherapy may not be effective. As such, predicting responses to chemotherapy before treatment is desirable.

Currently, immune checkpoint inhibitors, such as PD-1 inhibitors, have attracted attention for cancer treatment $[5,6]$. Accordingly, immune factors have been found to be important in cancer prognosis and response to chemotherapy, with reports showing a relationship between lymphocyte infiltration into the tumor and chemotherapy response, as well as findings suggesting that immunological factors, such as the neutrophil-lymphocyte ratio (NLR), are effective in predicting responses to chemotherapy [7-12]. Indeed, predicting responses to chemotherapy through general tests, such as blood tests, as well as the identification of several markers, will be of considerable benefit. Some reports have shown that lgG, one of the immunolocalize factors, is involved in cancer immunity through antibody-dependent cellular cytotoxicity (ADCC) [13]. Therefore, the current study aimed to investigate the utility of serum IgG levels in predicting the response to chemotherapy.

\section{Materials And Methods}

\section{Patients}

Among the patients who underwent esophagectomy after neoadjuvant chemotherapy at Nagoya City University Hospital between December 2012 and June 2019, 130 cases who (1) had histologically confirmed ESCC following biopsy and (2) received neoadjuvant chemotherapy were included in this study. Those who received chemotherapy due to unresectable ESCC (e.g., clinical M1 disease) were excluded. Among the 130 cases, 44 had no serum IgG measurements prior to neoadjuvant chemotherapy, while 1 underwent chemoradiation therapy, leaving 85 cases. Moreover, four cases who did not undergo surgery at the patient's request and another four who underwent palliative surgery due to intraoperative unresectable findings were excluded. Ultimately, 77 cases were enrolled herein (Fig. 1). The Union for International Cancer Control Tumor-Node-Metastasis Classification (7th edition) was used for staging.

This retrospective study was approved by the Institutional Review Board and the Ethics Committee of Nagoya City University Graduate School of Medical Sciences (reception number 60-18-0008), and informed consent was obtained from each patient.

\section{Neoadjuvant chemotherapy}

By 2016, our institution had introduced DCF as neoadjuvant chemotherapy for ESCC. DCF therapy was selected for patients below 75 years old in whom chemotherapy could be safely administered based on their medical history. For FP therapy, cisplatin $\left(80 \mathrm{mg} / \mathrm{m}^{2}\right)$ was administered on day 1 , while 5 -FU (800 
$\mathrm{mg} / \mathrm{m}^{2}$ ) was administered on days $1-5$, with one course lasting 28 days. For DCF consisting of FP and docetaxel, cisplatin $\left(70 \mathrm{mg} / \mathrm{m}^{2}\right)$ and docetaxel $\left(70 \mathrm{mg} / \mathrm{m}^{2}\right)$ were administered on day 1, while 5-FU (700 $\mathrm{mg} / \mathrm{m}^{2}$ ) was administered on days $1-5$, with one course lasting 28 days [14]. A total of two chemotherapy courses had been planned, while surgery was performed approximately 4-6 weeks after chemotherapy. When Grade 3 or above adverse events were observed, the dose was reduced by up to $25 \%$. However, when serious myelosuppression, renal dysfunction, or impaired liver function were observed, chemotherapy was stopped midway through the course and surgery was performed without the second course.

\section{Evaluating neoadjuvant chemotherapy response}

Response to neoadjuvant chemotherapy was evaluated according to the Japanese Classification of Esophageal Cancer, 11th Edition [15].

Up to 5 large-sized lymph nodes were targeted from among 10-mm or more enlarged lymph nodes. Cases wherein the sum of the major diameters of the target lesions decreased by $30 \%$ or more was defined as PR, while those wherein the sum of the major diameters increased by $20 \%$ or more was defined as PD. The remaining cases were defined as SD.

Among cases who had no enlarged lymph nodes over $10 \mathrm{~mm}$, response was determined based on the primary site of esophageal cancer. Cases wherein the major axis of the primary esophagus cancer decreased by $30 \%$ or more were defined as PR, while those wherein the major axis of the primary esophagus cancer increased by $\mathbf{2 0 \%}$ or more were defined as PD. Moreover, cases wherein upper gastrointestinal endoscopy showed reduced or flattened tumor or ulcer margin ridges or thinned or clean ulcer bases were defined as PR, while others were defined as SD.

\section{Pathological response to chemotherapy}

The degree of histopathological tumor regression in the surgical specimen was classified into four categories. The extent of viable residual carcinoma at the primary site was assessed semiquantitatively based on the estimated percentage of viable residual carcinoma in relation to the macroscopically identifiable tumor bed that was evaluated histopathologically. The percentage of viable residual tumor cells within the entire cancerous tissue was assessed as follows: Grade 3, no viable residual tumor cells (pathological complete response); Grade 2, less than one-third residual tumor cells; Grade 1b, more than one-third but less than two-thirds residual tumor cells; Grade $1 \mathrm{a}$, more than $2 / 3$ residual tumor cells; and Grade 0 , almost all residual tumor cells.

\section{Statistical analysis}


The association between serum IgG levels and response to chemotherapy was assessed using the Mann-Whitney $U$ test. The cutoff serum IgG levels was determined as the point maximizing the Youden index in the receiver operating characteristic (ROC) curve. comparison between groups was performed using the Chi-square test. A column with few cases was analyzed using Fisher's exact test. Logistic regression analysis using the backward elimination technique to derive a potentially suitable set of predictors was performed for each outcome parameter. All statistical analyses were performed using EZR [16], a graphical interface for $R$, with $p$-values $<0.05$ indicating statistical significance. More precisely, EZR is a modified version of $\mathrm{R}$ commander designed to add statistical functions frequently used in biostatistics.

\section{Results}

\section{Patient characteristics}

Table 1 summarizes the clinical characteristics of cases included herein. Approximately $90 \%$ of the cases were male, with 31 (40\%) receiving DCF. Moreover, 60 cases (71\%) received two cycles of chemotherapy, whereas $25(29 \%)$ received only one cycle due to severe adverse events.

\section{Response to neoadjuvant chemotherapy}

Among the 77 patients included herein, 58 had swollen lymph nodes larger than $10 \mathrm{~mm}$, with the response to chemotherapy being determined using the rate of change of the target lesions. In other patients, the response was determined using the primary esophageal lesion. Accordingly, 37 cases were classified as PR, 39 as SD, and 1 as PD, respectively. None of the cases were classified as CR. This study divided cases into two groups: the effective response group (PR) and ineffective response group (SD and PD).

\section{Chemotherapy regimen}

The effective response group tended to have more cases receiving DCF, although no significant difference was noted $(p=0.067)$. However, the effective response group had significantly more cases who received two chemotherapy cycles than one cycle $(p<0.001)$.

\section{Relationship between chemotherapy response and serum IgG level}

Patients included herein had a serum IgG level ranging from 460 to $2223 \mathrm{mg} / \mathrm{dL}$. The median [25th percentile (Q1), 75th percentile (Q3)]) serum IgG level in the effective $(n=37)$ and ineffective $(n=40)$ 
response groups were $976(871,1087)$ and $1227.5(1087,1466)$, respectively (Fig. 2). The effective group had a significantly lower serum IgG level than the ineffective group $(p<0.001)$.

The ROC curve was created using "effective" as the target, with the area under curve being $79.8 \%$. The cutoff serum IgG value at which the Youden index was maximized was determined to be $1087 \mathrm{mg} / \mathrm{dL}$ (sensitivity 0.757 , specificity 0.750 ) (Fig. 3A).

Using the determined cutoff value, cases were then divided into high (39 cases) and low (38 cases) IgG groups. Although the high IgG group was older than the low IgG group, no significant differences in gender, final $\mathrm{T}$ factor, final $\mathbf{N}$ factor, chemotherapy regimen, and number of chemotherapy cycles were observed between both groups. The low IgG group had significantly more cases who had effective response to chemotherapy compared to the high IgG group (Fig. 3B).

\section{Univariate and multivariate analyses}

To identify independent predictors for the response to chemotherapy, clinicopathological factors were assessed using univariate and multivariate logistic regression analyses. Accordingly, univariate analysis identified age (odds ratio $=0.237,95 \% \mathrm{Cl}=0.086-0.649 ; p=0.005$ ), neoadjuvant chemotherapy cycles (odds ratio $=9.120,95 \% \mathrm{Cl}=2.720-30.600 ; p<0.001$ ), neutrophil count (odds ratio $=0.210,95 \% \mathrm{Cl}=$ $0.067-0.658 ; p=0.007$ ), lymphocyte count (odds ratio $=0.095,95 \% \mathrm{Cl}=0.159-0.454 ; p=0.003$ ), and IgG levels (odds ratio $=0.107,95 \% \mathrm{Cl}=0.038-0.302 ; p<0.001$ ) as significant predictors for the response to chemotherapy. However, multivariate analysis showed that only neoadjuvant chemotherapy cycles (odds ratio $=16.700,95 \% \mathrm{Cl}=2.990-93.300 ; p=0.001$ ) and IgG levels (odds ratio $=0.085,95 \% \mathrm{Cl}=0.019-$ $0.382 ; p=0.001$ ) were independent predictors for the response to chemotherapy in ESCC (Table 2).

\section{Pathological findings}

All cases underwent esophagectomy, after which the relationship between histopathological response and serum IgG value was investigated. The number of cases according to each grade is presented in Figure 4A. Effective pathological response was defined as Grade 1b or higher (less than two-thirds residual tumor cells) was defined to be pathologically effective. Accordingly, cases with effective pathological response had significantly lower pretreatment serum IgG levels compared to those who did not $(p=0.006)$ (Fig. 4B).

\section{Discussion}

While studies have shown that neoadjuvant chemotherapy is beneficial for improving the prognosis of stage II/III esophageal cancer [2], not all cases exhibit an effective response to chemotherapy. As such, predicting response before treatment may further improve the prognosis for esophageal cancer. Recently, 
a number of studies have attempted to predict the response to chemotherapy $[8,9,12,17]$, with their findings suggesting the utility of certain immunological factors.

Among the immunological factors, the current study focused on IgG levels. One example of IgG-mediated immunity is $A D C C$, wherein immunoglobulin binds to the surface antigen of the tumor, NK cells recognize its Fc region and binds to it, subsequently damaging tumor cells [18]. Regarding the association between ADCC activity and chemotherapy, trastuzumab for breast cancer has been shown to activate ADCC and exerts anticancer effects [19]. Moreover, studies have shown that chemotherapy is effective in cases where lymphocyte tumor infiltration is high $[20,21]$.

While reports have found that serum IgG was associated with prognosis in other carcinomas [22, 23], no study has shown a relationship between serum IgG levels and response to chemotherapy. Considering that serum IgG levels can be easily measured using blood tests prior to chemotherapy, it can therefore be an important factor for determining the subsequent treatment provided that it can predict the response to chemotherapy.

Previous reports have suggested that the NLR can be useful for predicting the response to chemotherapy in various malignant tumors $[8,9,13]$. The current study also found that immunological factors, such as neutrophil count, were useful for predicting response to chemotherapy, although IgG levels were more predictive and had been identified as an independent predictor.

Although the association between other immunological factors and response to chemotherapy have been established, it remains unclear why serum IgG levels are associated with response to chemotherapy. Given that immune function also depends on systemic inflammation status, patients with high immune disease may have suppressed anti-tumor activity of cytotoxic $T$ lymphocytes, thereby promoting unsatisfactory response to chemotherapy. Reports have shown that high serum neutrophil levels were associated with systemic inflammation, not only immunity to cancer. Therefore, response to chemotherapy in such cases may be poor [8].

The current study found that chemotherapy was often ineffective in cases with high serum IgG levels, which is related not only to cancer immunity but also to systemic inflammation. As such, immunity to cancer may have been compromised in cases with systemic inflammation, resulting in poor response to chemotherapy.

\section{Abbreviations}

ADCC

Antibody-dependent cellular cytotoxicity

DCF

Docetaxel, cisplatin, and 5-FU

ESCC

Esophageal squamous cell cancer 
FP

5-fluorouracil and cisplatin

NLR

Neutrophil-lymphocyte ratio

\section{Declarations}

Ethics approval and consent to participate

This retrospective study was approved by the review board of Nagoya City University Graduate School of Medical Sciences (reception number: 60-18-0008).

Consent for publication

Approved.

Availability of data and materials

The datasets used during the current study are available from the corresponding author on reasonable request.

Competing interests

The authors declare that they have no competing interests.

Funding

None.

Contributions

All authors contributed to the study conception and design. Material preparation and data collection were performed by all authors. Material analysis was performed by SN. SN wrote the manuscript. RO, SH, SF, TO, HS, TT and ST participated in revising the manuscript. All authors have read and approved the final manuscript.

Acknowledgements

Not applicable.

Authors' information

Seiichi Nakaya ${ }^{1}$, Ryo Ogawa ${ }^{1}$, Shunsuke Hayakawa ${ }^{1}$, Shiro Fujihata ${ }^{1}$, Tomotaka Okubo ${ }^{1}$, Hiroyuki Sagawa ${ }^{1}$, Tatsuya Tanaka ${ }^{1}$, Hiroki Takahashi ${ }^{1}$, Yoichi Matsuo $^{1}$, Shuji Takiguchi ${ }^{1}$ 
${ }^{1}$ Department of Gastroenterological Surgery, Nagoya City University Graduate School of Medical Sciences, 1-Kawasumi, Mizuho-cho, Mizuho-ku, Nagoya City, Aichi 467-8602, Japan

Corresponding author

Seiichi Nakaya

nakaya22@med.nagoya-cu.ac.jp

\section{References}

1. Bray F, Ferlay J, Soerjomataram I, Siegel RL, Torre LA, Jemal A. Global cancer statistics 2018: GLOBOCAN estimates of incidence and mortality worldwide for 36 cancers in 185 countries. CA Cancer J Clin. 2018;68:394-424.

2. Ando $\mathrm{N}$, Kato $\mathrm{H}$, Igaki $\mathrm{H}$, Shinoda $\mathrm{M}$. A randomized trial comparing postoperative adjuvant chemotherapy with cisplatin and 5-fluorouracil versus preoperative chemotherapy for localized advanced squamous cell carcinoma of the thoracic esophagus (JCOG9907). Ann Surg Oncol. 2012;19:68-74.

3. Hara H, Tahara M, Daiko H, Kato K, Igaki H, Kadowaki S, Tanaka Y, Hamamoto Y, Matsushita H, Nagase M, Hosoya Y. Phase II feasibility study of preoperative chemotherapy with docetaxel, cisplatin, and fluorouracil for esophageal squamous cell carcinoma. Cancer Sci. 2013;104:1455-60.

4. Yamasaki M, Miyata H, Tanaka K, Shiraishi O, Motoori M, Peng YF, Yasuda T, Yano M, Shiozaki H, Mori M, Doki Y. Multicenter phase I/II study of docetaxel, cisplatin and fluorouracil combination chemotherapy in patients with advanced or recurrent squamous cell carcinoma of the esophagus. Oncology. 2011;80:307-13.

5. Kojima T, Doi T. Immunotherapy for esophageal squamous cell carcinoma. Curr Oncol Rep. 2017;19:33.

6. Kudo T, Hamamoto Y, Kato K, Ura T, Kojima T, Tsushima T, Hironaka S, Hara H, Satoh T, Iwasa S, Muro K, Yasui H, Minashi K, Yamaguchi K, Ohtsu A, Doki Y, Kitagawa Y. Nivolumab treatment for oesophageal squamous-cell carcinoma: an open-label, multicentre, phase 2 trial. Lancet Oncol. 2017;18:631-9.

7. Zheng X, Song X, Shao Y, Xu B, Hu W, Zhou Q, Chen L, Zhang D, Wu C, Jiang J. Prognostic role of tumor-infiltrating lymphocytes in esophagus cancer: a meta-analysis. Cell Physiol Biochem. 2018;45:720-32.

8. Sato Y, Gonda K, Harada M, Tanisaka Y, Arai S, Mashimo Y, Iwano H, Sato H, Ryozawa S, Takahashi T, Sakuramoto S, Shibata M. Increased neutrophil-to-lymphocyte ratio is a novel marker for nutrition, inflammation and chemotherapy outcome in patients with locally advanced and metastatic esophageal squamous cell carcinoma. Biomed Rep. 2017;7:79-84.

9. Wang F, Liu ZY, Xia YY, Zhou C, Shen XM, Li XL, Han SG, Zheng Y, Mao ZQ, Gong FR, Tao M, Lian L, Li W. Changes in neutrophil/lymphocyte and platelet/lymphocyte ratios after chemotherapy correlate 
with chemotherapy response and prediction of prognosis in patients with unresectable gastric cancer. Oncol Lett. 2015;10:3411-8.

10. Sudo T, Nishida R, Kawahara A, Saisho K, Mimori K, Yamada A, Mizoguchi A, Kadoya K, Matono S, Mori N, Tanaka T, Akagi Y. Clinical impact of tumor-infiltrating lymphocytes in esophageal squamous cell carcinoma. Ann Surg Oncol. 2017;24:3763-70.

11. Ladoire S, Mignot G, Dabakuyo S, Arnould L, Apetoh L, Rébé C, Coudert B, Martin F, Bizollon MH, Vanoli A, Coutant $C$, Fumoleau $P$, Bonnetain $F$, Ghiringhelli $F$. In situ immune response after neoadjuvant chemotherapy for breast cancer predicts survival. J Pathol. 2011;224:389-400.

12. Lo CS, Sanii S, Kroeger DR, Milne K, Talhouk A, Chiu DS, Rahimi K, Shaw PA, Clarke BA, Nelson BH. Neoadjuvant chemotherapy of ovarian cancer results in three patterns of tumor-infiltrating lymphocyte response with distinct implications for immunotherapy. Clin Cancer Res. 2017;23:92534.

13. Gutkin DW, Shurin MR. Clinical evaluation of systemic and local immune responses in cancer: time for integration. Cancer Immunol Immunother. 2014;63:45-57.

14. Nakamura $K$, Kato $K$, Igaki $H$, Ito $Y$, Mizusawa J, Ando N, Udagawa $H$, Tsubosa Y, Daiko H, Hironaka S, Fukuda H, Kitagawa Y. Three-arm phase III trial comparing cisplatin plus 5-FU (CF) versus docetaxel, cisplatin plus 5-FU (DCF) versus radiotherapy with CF (CF-RT) as preoperative therapy for locally advanced esophageal cancer (JCOG1109, NEXT study. Jpn J Clin Oncol. 2013;43:752-5.

15. Japan Esophageal Society. Japanese Classification of Esophageal Cancer. Esophagus, 11th edition 2017;14:1-36.

16. Kanda Y. Investigation of the freely available easy-to-use software "EZR" for medical statistics. Bone Marrow Transplant. 2013;48:452-8.

17. Hirahara T, Arigami T, Yanagita S, Matsushita D, Uchikado Y, Kita Y, Mori S, Sasaki K, Omoto I, Kurahara H, Maemura K, Okubo K, Uenosono Y, Ishigami S, Natsugoe S. Combined neutrophillymphocyte ratio and platelet-lymphocyte ratio predicts chemotherapy response and prognosis in patients with advanced gastric cancer. BMC Cancer. 2019;19:672.

18. Wang W, Erbe AK, Hank JA, Morris ZS, Sondel PM. NK cell-mediated antibody-dependent cellular cytotoxicity in cancer immunotherapy. Front Immunol. 2015;6:368.

19. Perez EA, Ballman KV, Tenner KS, Thompson EA, Badve SS, Bailey H, Baehner FL. Association of Stromal Tumor-Infiltrating Lymphocytes With Recurrence-Free Survival in the N9831 adjuvant trial in patients with early-stage HER2-positive breast cancer. JAMA Oncol. 2016;2:56-64.

20. Denkert C, Loibl S, Noske A, Roller M, Müller BM, Komor M, Budczies J, Darb-Esfahani S, Kronenwett R, Hanusch C, von Törne C, Weichert W, Engels K, Solbach C, Schrader I, Dietel M, von Minckwitz G. Tumor-associated lymphocytes as an independent predictor of response to neoadjuvant chemotherapy in breast cancer. J Clin Oncol. 2010;28:105-13.

21. Brown JR, Wimberly H, Lannin DR, Nixon C, Rimm DL, Bossuyt V. Multiplexed quantitative analysis of CD3, CD8, and CD20 predicts response to neoadjuvant chemotherapy in breast cancer. Clin Cancer Res. 2014;20:5995-6005. 
22. Sheng Z, Liu Y, Qin C, Liu Z, Yuan Y, Hu F, Du Y, Yin H, Qiu X, Xu T. IgG is involved in the migration and invasion of clear cell renal cell carcinoma. J Clin Pathol. 2016;69:497-504.

23. Saito H, Miyatani K, Kono Y, Murakami Y, Kuroda H, Matsunaga T, Fukumoto Y, Takano S, Osaki T, Fujiwara Y. Decreased serum concentration of total IgG is related to tumor progression in gastric cancer patients. Yonago Acta Med. 2017;60:119-25.

\section{Tables}

Due to technical limitations, table $1 \& 2$ is only available as a download in the Supplemental Files section.

\section{Figures}

\section{NAC (FP or DCF) for ESCC from December 2012 to June 2019 $(n=130)$}

No data of serum $\lg G(n=44)$

Chemoradiation therapy $(n=1)$

No surgery due to patient will $(n=4)$

Palliative surgery because of unresectability $(n=4)$

Radical surgery $(n=77)$

Figure 1

Flow chart for study inclusion 


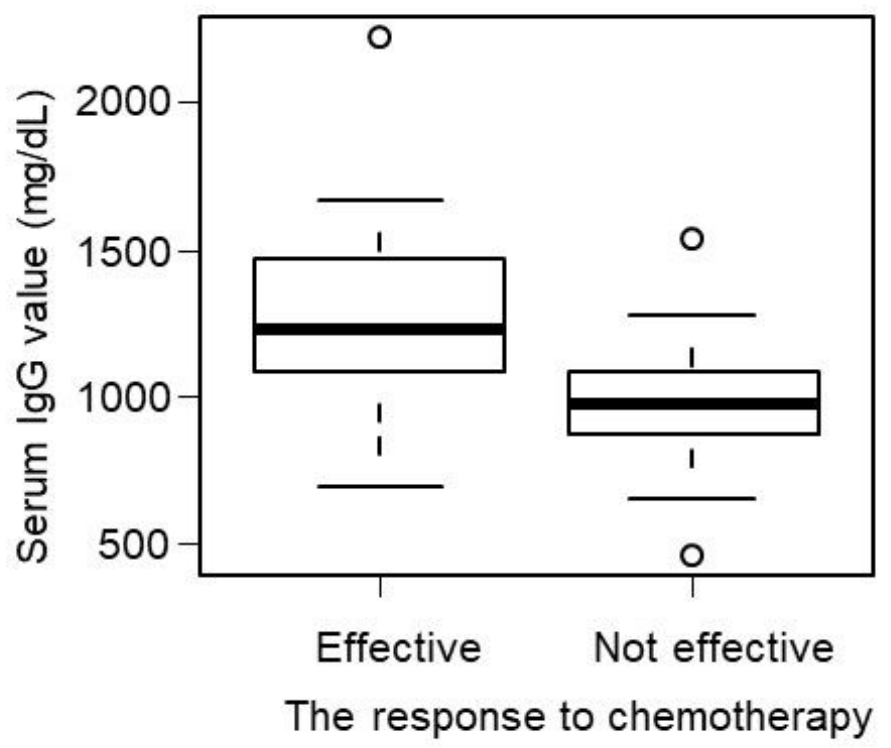

Figure 2

Association between serum IgG levels and response to chemotherapy 


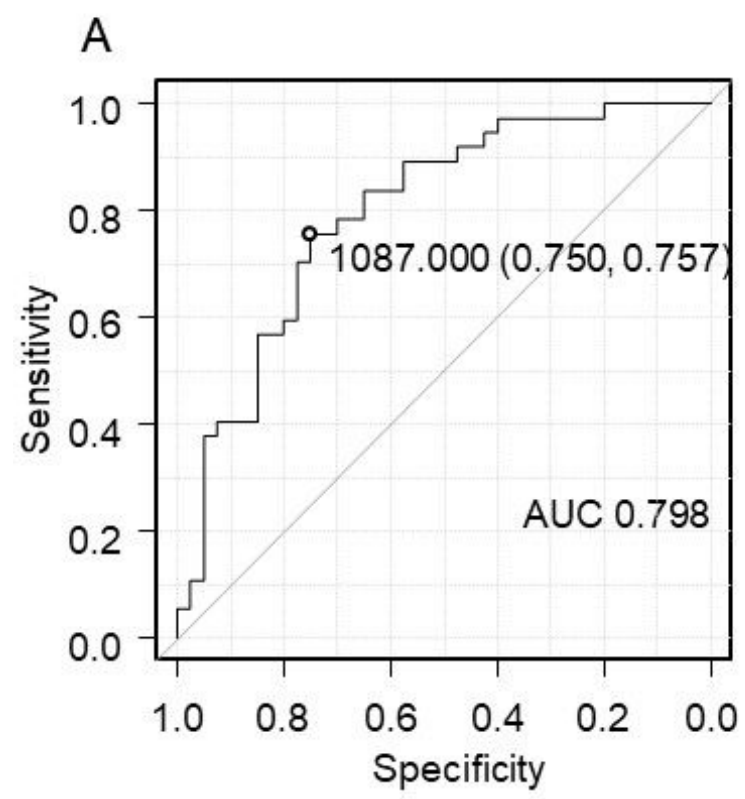

B

\begin{tabular}{|c|c|c|c|}
\hline & High group & Low group & $p$ value \\
\hline Age & & & * \\
\hline Median $(25 \%, 75 \%$ quantile) & $\begin{array}{l}69 \\
(66,72.5)\end{array}$ & $\begin{array}{l}65.5 \\
(61,70)\end{array}$ & 0.044 \\
\hline Gender, $\mathrm{n}$ & & & $\star \star$ \\
\hline Male/Female & $34 / 5$ & $35 / 3$ & 0.711 \\
\hline Final $T$ factor, $n$ & & & * \\
\hline T0-2/T3-4 & $20 / 19$ & $18 / 20$ & 0.908 \\
\hline Final $\mathrm{N}$ factor, $\mathrm{n}$ & & & $\star \star \star \star$ \\
\hline No/N1-4 & $16 / 21$ & $16 / 22$ & 0.898 \\
\hline \multirow{2}{*}{$\begin{array}{l}\text { Chemotherapy regimen, } n \\
\text { FP/DCF }\end{array}$} & & \multirow[b]{2}{*}{$21 / 17$} & $* \star \star$ \\
\hline & $25 / 14$ & & 0.577 \\
\hline \multirow{2}{*}{$\begin{array}{l}\text { Cycles of chemotherapy, } n \\
2 / 1\end{array}$} & & \multirow[b]{2}{*}{$27 / 11$} & $\star \star \star \star$ \\
\hline & $25 / 14$ & & 0.683 \\
\hline \multirow{3}{*}{$\begin{array}{l}\text { Response to chemotherapy, } n \\
\text { Effective/Not-effective }\end{array}$} & & \multirow[b]{2}{*}{$28 / 10$} & $\star \star \star \star$ \\
\hline & $9 / 30$ & & $<0.001$ \\
\hline & & $\begin{array}{l}\text { Mann- } \\
\text { Fisher' } \\
\text { X2 test }\end{array}$ & $\begin{array}{l}\text { hitney } U \text { test } \\
\text { exact test }\end{array}$ \\
\hline
\end{tabular}

Figure 3

A. Receiver operating characteristic (ROC) curve of serum IgG levels for predicting the response to chemotherapy. B. Association between clinical characteristics and response to chemotherapy according to serum IgG levels. 


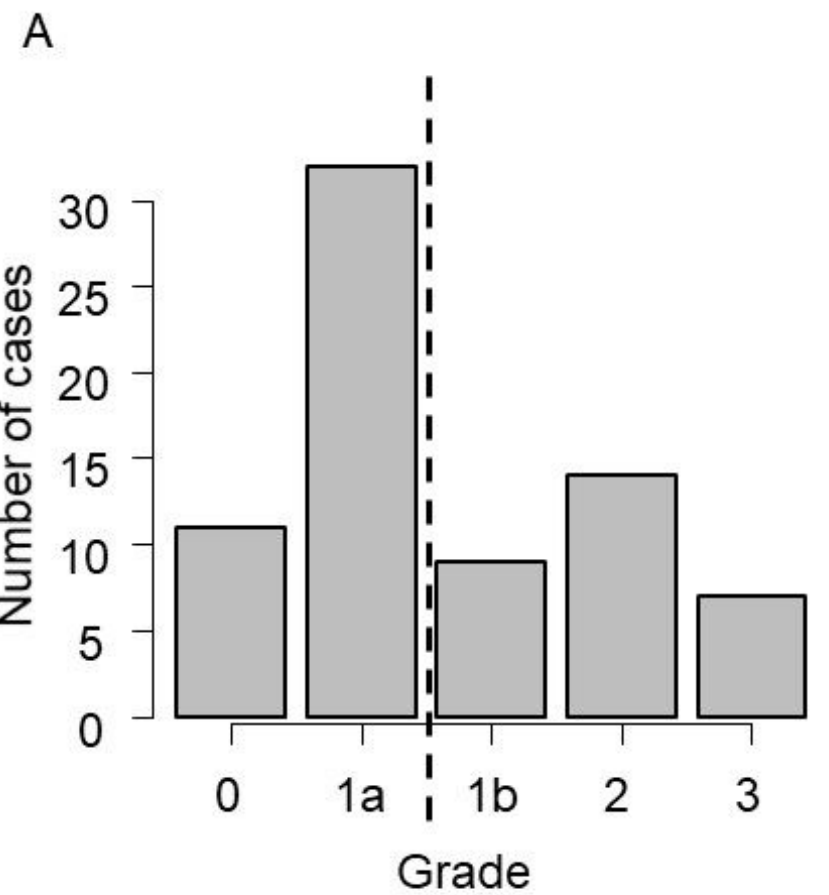

B

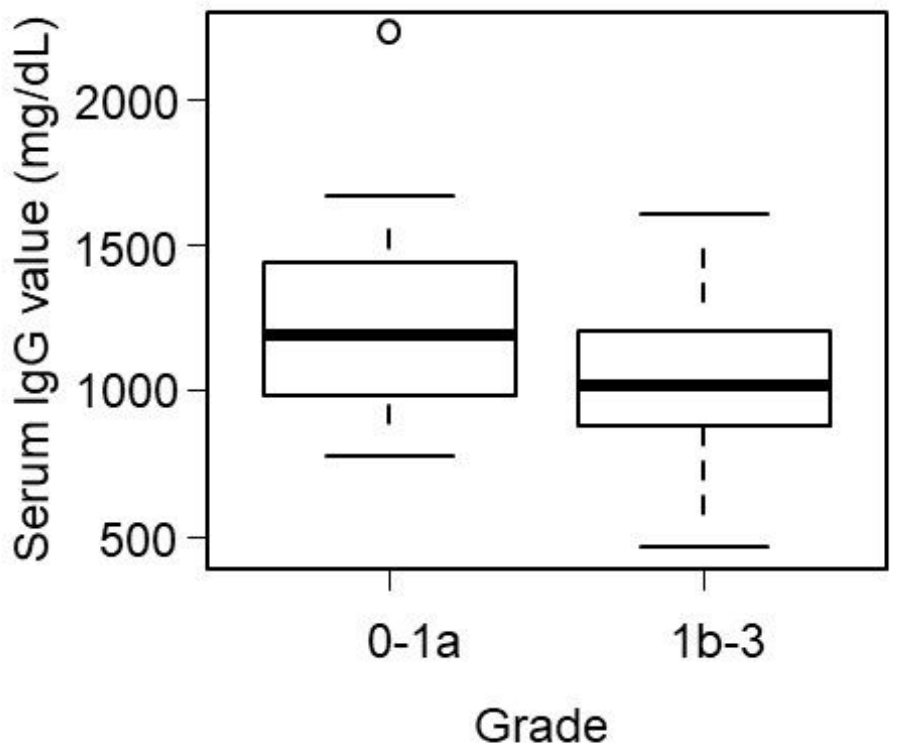

Figure 4

A. Distribution of grades according to pathological findings. B. Association between serum IgG levels and response to chemotherapy according to pathological findings.

\section{Supplementary Files}

This is a list of supplementary files associated with this preprint. Click to download.

- Table1.xls

- Table2.xls 